\title{
MOSAICOS ROMANOS DE LOS BAÑOS DE LA REINA (CALPE, ALICANTE)
}

\section{THE BAÑO DE LA REINA ROMAN MOSAICS (CALPE, ALICANTE)}

\author{
por \\ LORENZO ABAD CASAL
}

RESUMEN En este trabajo se estudia un grupo de nueve mosaicos, algunos de los cuales se conocen desde el siglo XVIII y otros han sido descubiertos recientemente. Se establecen tres grupos, datados entre el siglo I d.C. y comienzos del III d.C.

\begin{abstract}
In this paper we study a group of nine mosaics. Some of them have been known from the XVIII Century, and some of them have been discovered recently. We establish three groups which range from the first century A.D. to the beginning of the third century A.D.
\end{abstract}

Palabras claves Mosaico. Romano. Bícromo.

Key words Mosaic. Roman. Bicrome.

\section{INTRODUCCIÓN}

El yacimiento arqueológico conocido como 'Los Baños de la Reina' de Calpe reúne uno de los conjuntos más numerosos de mosaicos romanos de la provincia de Alicante, superado tan sólo por los de la colonia Iulia Ilici Augusta y su entorno. El que casi todos estos mosaicos, en su mayoría perdidos, procedan de excavaciones antiguas, sin contextos dignos de confianza, acrecienta la importancia de los descubiertos recientemente en Calpe, pues lo han sido en el marco de excavaciones programadas.

Durante estos trabajos se ha puesto al descubierto parte de un conjunto residencial con varios mosaicos que vienen a sumarse a los ya recogidos e ilustrados a finales del siglo XVIII por el viajero ilustrado Antonio José de Cavanilles; hacia 1965, y en el marco de unos trabajos previos de delimitación de las áreas arqueológicas, Manuel Pellicer encontró alguno más (Fig. 1); y en los últimos años, en unas actuaciones 
que con este mismo fin ha llevado a cabo un equipo dirigido por Juan M. Abascal, se ha puesto al descubierto un conjunto del mayor interés ${ }^{1}$ (Lám. 1).

Lo que Antonio José de Cavanilles recoge en su obra Observaciones sobre la Historia Natural, Geografia, Agricultura, Población y Frutos del Reyno de Valencia, publicado en Madrid en el año 1797, pp. 228 y sigs, es un conjunto de mosaicos de diferente tipo y clase, que describe de manera bastante prolija; a uno de ellos corresponderá el excavado después por Pellicer. Todos son bícromos, con fondo blanco y motivos negros, excepto uno de ellos, que muestra la disposición contraria.

Estos mosaicos han sido poco citados en la bibliografía especializada. Entre estas menciones podemos citar un trabajo de A. Balil, que ya puso en relación los mosaicos de Cavanilles con el de Pellicer ${ }^{2}$ y una cita de M. Guardia que recoge los datos ya conocidos ${ }^{3}$.

\section{DESCRIPCIÓN}

1. El mosaico pavimentaba una pieza cuadrada delimitada por una banda y dos filetes (Fig. 2). El campo era una retícula de bandas de cuadrados en punta unidos por dos de sus ángulos; las líneas principales de la red corren de izquierda a derecha en el dibujo y mantienen el esquema original sin interrupción; en cambio, las que van de arriba a abajo, están compuestas por series de un cuadrado completo en el centro y dos medios a cada lado, que vienen a unir con las esquinas de dos de la banda principal.

Estas bandas enmarcan un conjunto de al menos 36 cuadrados formados por una banda delimitada por dos filetes de diferente ancho y un motivo decorativo en su interior; todos éstos habían desaparecido excepto dos que se conservaban completos y tres en parte. En cualquier caso, era suficiente para observar que los motivos variaban de uno a otro: un juego de cuadrado en punta y medios cuadrados en uno, diagonales con segmentos de círculos en otro y segmentos de círculo sin diagonales, con puntos en su interior, en el tercero.

2. El segundo mosaico (Fig. 3) corresponde a una pieza alargada, cortada en chaflán al menos por uno de sus lados y formada por una serie de 'ladrillos' -en palabra de Cavanilles- rectangulares de teselas blancas delimitados por filetes negros que marcarían las teóricas llagas del pavimento.

3. Habitación ligeramente trapecial, en la que sobre fondo blanco aparece una banda que forma una especie de rectángulo con tres de sus lados curvos, en una composición bastante extraña (Fig. 4). En su lado cóncavo, el espacio exterior entre él y el muro se rellenó con un roleo de vid. En el interior, de una crátera de grandes asas sobreelevadas surge una vid en torno a la cual revolotean dos amorcillos que cogen sendos racimos, un ave con las alas plegadas que se acerca a un tercero y lo que parece una rata en su parte superior.

1. A. J. Cavanilles, Observaciones sobre la historia natural, geografía, agricultura, población y frutos del Reino de Valencia, Madrid, 1797, IV, 226-232. M. Pellicer, 'Excavaciones en el yacimiento romano de Baños de la Reina, Calpe, Alicante', $N A H$, 8-9, 1-3, 1964-65 [1966] pp. 171-176. J.M. Abascal, R. Cebrián, F. Sala, "El vikus romano de 'Baños de la Reina' (Calpe, Alicante)", Los orígenes del cristianismo en Valencia y su entorno, Valencia, 2000, 49-64. Los trabajos que han dado pie al descubrimiento de los nuevos mosaicos se han realizado entre los años 1993 y 1999, y han sido dirigidos por Juan M. Abascal y Rosario Cebrián. Han continuado otros anteriores, que entre los años 1986 y 1988 tuvieron como objetivo delimitar la zona arqueológica y cuyos directores fueron, en sucesivos momentos, Lorenzo Abad, Feliciana Sala, José Luis Simón y Joaquim Bolufer.

2. A. Balil, Antonio José Cavanilles. Materiales para la historia dé la arquitectura española, 1. Excavaciones en Calpe, 1797. Studia Archaeologica, 1, Santiago de Compostela, 1970.

3. M. Guardia, Los mosaicos de la Antigüedad Tardía en Hispania. Estudios de iconografía, Barcelona, 1992, 380; los data, siguiendo la tradición, en el siglo IV d.C. 
Este mosaico corresponde al mismo que documentó Pellicer dos siglos después, y ambos debían flanquear de forma simétrica una especie de receptáculo circular dotado de un desagüe (Figs. 1 y 5). Este presenta un dibujo formado por una crátera semejante a la Cavanilles, de la que sale un racimo de vid sobre la que aparece un erote y un ave de forma similar-aunque no idéntica-a la de aquel. En el dibujo de Pellicer se observa la base del marco y el arranque de uno de sus lados, que aparece como recto según, aunque de la observación de lo que se conserva en el Museo Arqueológico Provincial de Alicante parece deducirse que el trazo era ligeramente curvo y similar por tanto al de Cavanilles (Fig. 5). Ambos fragmentos son sin duda piezas complementarias, que pertenecían a un mismo mosaico, por más que el muro superior del dibujo de Cabanilles parezca indicar que eran independientes.

4. El último mosaico (Fig. 6) es de fondo blanco delimitado por una banda negra; su conjunto forma una L y según Cavanilles constituía la parte interior de una habitación cuadrada cuya zona anterior carecía de mosaico.

5. La pieza que se conserva más completa es la del patio poligonal de la mansión excavada en los últimos años (Fig. 7). Aunque muy dañado, permite recomponer en su casi totalidad el esquema decorativo, excepción hecha de la parte central. Pueden identificarse tres partes principales (Fig. 8):

a. Un emblema casi totalmente perdido, que a juzgar por unas pocas teselas encontradas en las proximidades pudo haber albergado algún motivo polícromo. Estuvo rodeado por una cenefa de postas, que debía marcar la transición al segundo cuerpo (Lám. 2).

b. Un cuerpo intermedio, bícromo, entre este motivo central y el murete que unía las basas de las columnas. Se componía, de dentro hacia fuera, de un conjunto de siete cenefas con los siguientes motivos (Fig. 9) (Lám. 3): 1. Roleo de hojas cuadripétales; 2 . Rosetas de seis puntas inscritas en un círculo y separadas por peltas que apoyan en la línea exterior de la banda; 3 . Motivos similares a los centrales de la banda anterior rodeados de otras rosetas de seis puntas de lados curvos inscritas a su vez en un círculo; 4. Rosetas hexapétalas inscritas en un círculo y con sus extremos unidos por husos similares a los pétalos; 5. Banda similar a la número 4; 6 . Banda formada por un enrejado en forma de equis con trazos de unión entre sus vértices superior e inferior; en los espacios por ellos delimitados, motivos de relleno en forma de peltas afrontadas y opuestas; 7. Roleo similar al de la segunda banda, pero en este caso formado por una vid con racimos y hojas.

c. Un cuerpo exterior, también bícromo (Fig. 8), de un ancho similar al anterior, y formado por un campo central y dos cenefas a cada lado. De dentro hacia fuera nos encontramos con una cenefa de cable, un roleo similar al primero del cuerpo anterior, un cuerpo central formado por un imbricado de escamas que forman líneas alternantes en blanco y negro (Lám. 4), otra cenefa de cable y un nuevo roleo bastante más estrecho que el anterior.

6. Mosaico bícromo que pavimenta una de las estancias termales (Fig. 7, núm. 1). El marco está formado por dos bandas negras separadas por un filete blanco y el esquema compositivo por motivos blancos sobre fondo negro (Fig. 10, Lám. 5). Una serie de líneas que se cruzan en ángulo recto forman una cuadrícula; en el interior de cada cuadrado, una esvástica que se relaciona con las de los contiguos configura una red que cubre toda la superficie. En la parte central se observan vestigios de un emblema cuadrangular formado por dos bandas negras separadas por una blanca; las dos exteriores contornean un cuadrado en cuyos ángulos se encuentra un basamento macizo, probable soporte de pilares o columnas que servirían de soporte a alguna estructura; entre una y otra, una cenefa de esvásticas de punta enlazadas, ahora en negro sobre blanco. 
7. Mosaico bícromo del que sólo se conservaba la parte más próxima a la pared, formada por una banda negra sobre fondo blanco, en la estancia número 9 de la figura 8 . No existe ningún otro indicio que permita reconstituir el resto de los motivos.

8. Pequeño fragmento de mosaico bícromo encontrado en las excavaciones de 1985 adosado a un muro. Se conservaban restos de dos bandas, negra la más próxima a la pared y blanca la exterior.

9. Mosaico de opus sectile (Lám. 6) en diferentes tipos de mármol ${ }^{4}$ formado por un juego de placas circulares que alternan con rosetas cuadripétalas -sólo se conservan medias, por estar adosadas al muro-, de la intersección de cuyas hojas nacen pequeños tallos apuntados.

\section{ESTUDIO ESTILÍSTICO Y CRONOLÓGICO}

De la simple observación de todos estos mosaicos se obtiene la impresión de que nos encontramos ante un conjunto relativamente homogéneo, tanto por el diseño decorativo-mosaicos exclusivamente bícromos, excepto el emblema del peristilo- como por el repertorio de motivos empleados. Todos los conservados comparten la técnica del dibujo negro sobre fondo blanco, excepto el número 6, que en su mayor parte muestra la inversa de blanco sobre negro.

Aunque la distinta forma de los mosaicos no facilita la uniformidad del esquema geométrico, los elementos interiores de relleno sí que mantienen una cierta homogeneidad: los motivos vegetales están relacionados con la vid (parras que salen de una crátera, roleos) y los únicos que no parecen pertenecer a esta planta comparten con ella también la forma de roleo.

El motivo decorativo del segundo cuadrado del mosaico número 1 (Fig. 2) es similar al de la cenefa número b6 del gran mosaico del peristilo (número 5) (Fig. 9), hasta tal punto que nos hace pensar que los motivos interiores de aquel corresponden en realidad a peltas esquematizadas en el dibujo.

En lo que se refiere a este gran mosaico del peristilo, las bandas que han podido reconstruirse son enormemente repetitivas (Fig. 9): en tres -contiguas, además-se repite el esquema de roseta hexapétala inscrita en un círculo más o menos complejo; en otros dos los roleos y en dos más las peltas, aunque estructuradas de forma distinta (Lám. 7). Existe una clara cadencia roleo-pelta-roseta-roseta-roseta-pelta-roleo.

Si agrupamos los mosaicos tomando en consideración los lugares de donde proceden, podemos hacer un primer apartado con los mosaicos número 1-2-3-4 (Figs. 2-6), correspondientes a una instalación posiblemente doméstica en la zona septentrional del yacimiento (Fig. 11). Parecen corresponder a un mismo conjunto y como tal lo estudiaremos. Un segundo grupo lo integran el gran mosaico número 5 (Fig. 6), del peristilo de la villa, y el sectile de una de las habitaciones que lo rodean (número 9). Y el tercero, los mosaicos número 6-7-8 (Fig. 10), correspondientes al mismo conjunto residencial, posiblemente a unas estancias termales de una fecha algo anterior.

El estudio de estos mosaicos resulta de todos modos bastante difícil. Por una parte se carece de contextos arqueológicos fiables tanto sobre los mosaicos como por debajo de ellos, lo que dificulta sobremanera la posibilidad de proponer cronologías con criterios arqueológicos ${ }^{5}$. Su estudio y adscripción temporal debe descansar, por consiguiente, sobre la base de un estudio estilístico y estructural interno; pero el escaso número de mosaicos conservados en el yacimiento y en el ámbito geográfico más próximo, así como la sencillez

4. Cf. capítulo dedicado al estudio de los mármoles en la memoria de excavación que se publicará próximamente.

5. En el caso del número 7 se ha procedido en las últimas campañas a la excavación de la cama en aquellos lugares donde la rotura del mosaico lo ha permitido, sin obtener ningún resultado de interés. 
de sus motivos decorativos, no permiten esperar grandes conclusiones ${ }^{6}$. Habría que recurrir, por tanto, al método tradicional de datación a través de paralelos, algo sobre lo que cada vez somos más escépticos, ya que siempre se puede encontrar un paralelo ad hoc en algún lugar más o menos remoto del ámbito romano.

En su mayor parte se trata de mosaicos bastante simples y - en los pocos que aún pueden verse in situde escasos recursos técnicos. No obstante, tenemos que cuidarnos de asociar simplicidad con antigüedad, pues lo que creemos que ocurre es que nos encontramos ante trabajos realizados por talleres formados por artesanos de recursos técnicos bastante limitados.

\section{Conjunto 1-2-3-4 (Figs. 2-6)}

Es el más completo, ya que está integrado por cuatro mosaicos de tipos y características bastante diferentes, aunque según se ha podido ver en el intento de reconstrucción del conjunto, pertenecientes todos a una misma unidad constructiva. En el conjunto prima la decoración de tipo geométrico, muy simple en los mosaicos 2 y 4, más compleja en el 1 y figurada en el 3.

En lo que sabemos por las notas de Cavanilles y de Pellicer, y por lo poco que se conserva en el Museo Provincial de Alicante, el conjunto es exclusivamente blanco y negro, sin atisbo alguno de policromía. El mosaico número 4 es extraordinariamente simple, pues consta de unas cenefas de color negro que bordean un espacio en forma de L de color blanco. Su sencillez y simplicidad no permiten más precisiones.

Los otros mosaicos son de mayor interés. El número 1, también bícromo, presenta un conjunto de casetones separados por bandas formadas por cuadrados y medios cuadrados en punta. El motivo de los casetones es bastante frecuente en todo el ámbito cronológico del Imperio, aunque se da con más frecuencia a lo largo del siglo II y de forma especial en las provincias centrales del Imperio ${ }^{7}$. Sin embargo, el elemento de separación de estos casetones resulta en el caso de Calpe muy sencillo y podríamos decir que arcaico, ya que se encuentra bastante alejado de los motivos más frecuentes en esos momentos para recordar formas más sencillas y antiguas.

Motivos de separación en forma de cuadrados en punta, y de medios cuadrados que forman triángulos unidos por su vértice-lo que Becatti denominaba clepsidrae-, son relativamente frecuentes en la musivaria romana ${ }^{8}$, y motivos similares rellenan también campos de mosaicos, con preferencia en épocas republicana y altoimperial ${ }^{9}$. No obstante, el motivo que como en este caso está formado por cuadrados en punta a cuyos vértices se unen triángulos es bastante más extraño.

El mosaico número 4 (Fig. 6) es asimismo de sencillez extrema. Reproduce un conjunto de losetas rectangulares de color blanco separadas por llagas negras, dispuestas ordenadamente. Este tipo de decoración se encuentra por primera vez en el entorno exterior de mosaicos antiguos, cuya parte central está con frecuencia

6. La mayor parte de los motivos decorativos son bandas y cenefas geométricas. Para un estudio en detalle de cada una de ellas pueden verse Ph. Bruneau, Exploration archéologique de Délos. Les mosaïques, París, 1972; A. Ovadiah, Geometric and Floral Patterns in Ancient Mosaics, Roma, 1980; y especialmente C. Balmelle, M. Blanchard Lemée, J. Christophe, J.P. Darmon, A.M. Guimier, H. Lavagne, R. Proudhomme, H. Stern, Le décor géométrique de la mosaïque romaine. Répertoire graphique et descriptif des compositions linéaires et isotropes, París, 1985.

7. Para mosaicos con casetones, vid. entre otros J. Lancha, Recueil Général des Mosaüques de la Gaule, III. Narbonnaise, 2. $X^{\text {eme }}$ Supplément à Gallia, núms. 242, 306, datados todos ellos a lo largo del siglo II d.C. Cf. también H. Stern, Recueil Général des Mosaïques de la Gaule, II. Lyonnaise, l, núms. Lyon 1 y Lyon 53, datados a comienzos del III d.C.

8. Ovadiah, 108, A26; En Mérida, los tenemos en la Casa del Mitreo y en la Casa Basílica; cf. A. Blanco, Mosaicos romanos de Mérida, Corpus de mosaicos romanos de España, I, Madrid, 1978, núms. 24 y 47, datados ambos en el siglo II d.C.

9. Cf. por ejemplo M.S. Pisapia, Mosaici antichi in Italia, Regione Prima, Stabiae, Roma, 1989, núm. 97, y el mosaico de Liria hoy en el Museo Arqueológico Nacional de Madrid: J.M. Blázquez et alii, Mosaicos romanos del Museo Arqueológico Nacional, Madrid, 1989, núm. 26, datado en época severiana. 
rodeada por cenefas del tipo 'muro de ciudad', pero continúa apareciendo con diversa suerte en mosaicos más tardíos, incluidos pavimentos de opus sectile ${ }^{10}$.

Por último, el mosaico número 3 es el de mayor interés, pues presenta una decoración figurada en negro sobre blanco, en forma de vides que salen de cráteras y cuyos frutos son recogidos por erotes con podaderas y cestos. Aves y roedores completan la decoración. La técnica decorativa es simple, las figuras carecen de contorno marcado, pues se encuentra delimitada por las mismas teselas del interior. Las formas son angulosas y las teselas negras se han perdido con mayor facilidad que las blancas. Todo el conjunto, por tanto, refleja una considerable sencillez y simplicidad técnica y ornamental, dando la impresión de haber sido realizado por un taller de no demasiados recursos técnicos.

Mosaicos con esta decoración son relativamente frecuentes en todo el ámbito del Imperio, si bien varían en gran medida la forma y los detalles ${ }^{11}$ y abarcan un amplio período cronológico que repite, en cada momento, las características básicas del repertorio iconográfico vigente ${ }^{12}$.

\section{Conjunto 5-9}

Se trata de un conjunto de mosaicos compuesto por el que pavimenta el gran patio central y el sectile de una de las habitaciones. El primero presenta un conjunto de bandas con decoración geométrica en su mayor parte, estando reducidos los motivos vegetales a distintos tipos de roleos. El deambulacro exterior se encuentra pavimentado con un motivo de escamas imbricadas. Todo el conjunto es blanco y negro, excepto quizás el motivo central, totalmente perdido, donde se han encontrado unas pocas teselas polícromas.

Pese a ser el mosaico de mayores dimensiones y el único encontrado en excavaciones recientes, poco es lo que podemos conocer acerca de su cronología; tan sólo que sobre él se acumulaban materiales revueltos de los siglos IV-V, lo que nos proporciona un término ante quem poco significativo. Los motivos que adornan las bandas nos informan de bastante poco, pues resultan muy comunes: las postas, los roleos, las rosetas de seis puntas encerradas en círculos, las peltas en diversas formas, son motivos bastante frecuentes en todo el mundo romano ${ }^{13}$. Su cronología, a falta de una argumentación arqueológica, tan sólo puede venir

10. Cf. varios mosaicos de Mérida, en J.M. Álvarez, Mosaicos romanos de Mérida. Nuevos hallazgos, Mérida, 1990, núm. 3 y A. Blanco, Mosaicos romanos de Mérida, Corpus de mosaicos romanos de España, I, Madrid, 1978, núm. 19, con propuestas de datación en los siglos IV y II d.C. respectivamente. Véase también el mosaico de Augst, en L. Berger y M. Joos, 'Observations stylistiques techniques et petrographiques sur la mosaïque aux gladiateurs d'Augst Suisse', en La mosaïque grécorromaine, I, 265ss, datado a fines del siglo II d.C. H. Stern, Recueil Général des mosaïques de la Gaule, II. Lyonnaise, l, París, 1967, núm. 46, data un mosaico de Lyon en la segunda mitad del siglo II d.C. Como ejemplo de mosaicos de opus sectile podemos indicar algunos pavimentos de Villa Adriana: F. Guidobaldi, Sectilia pavimenta di Villa Adriana, Roma, 1994, núms. 154, $161,180$.

11. El ejemplo más próximo de mosaico con erotes vendimiadores es el del Tigerreiter de Sagunto ilustrado y descrito a fines del siglo XVIII por el Conde de Lumaires; vide Inscripciones y Antigüedades del Reino de Valencia, Madrid, 1979, lám. 12. Pero su nómina es amplísima; los hay en un mosaico ya citado de la Travesía de Pedro María Plano, en Mérida; cf. J.M. Álvarez, Mosaicos romanos de Mérida. Nuevos hallazgos, Mérida, 1990, núm. 3, datado en el siglo IV, con erotes con podón y cestos; y también en Mérida en el mosaico de la vendimia de la Casa del Anfiteatro, aunque en este caso en una composición muy diferente a la de Calpe. Son también abundantes en mosaicos norteafricanos, como uno de Oudna de época antonina, y otros de Thuburbo Maius y otros lugares; para ello puede verse el capítulo 'The Triclinium', en la obra de Ch. Kondoleon, Domestic and Divine. Roman Mosaics in the House of Dionysos, London, 1994, 232 ss. También en la Insula dell' Aquila de Ostia, datado hacia mediados del siglo III d.C.; cf. G. Becatti, Scavi di Ostia, Mosaici e pavimenti marmorei, Roma, 1961, núm. 373. Y en un monumento funerario de Via Portuense en Roma, de mediados del siglo II dC; cf. Notizie segli Scavi, XL-XLI, 1986-87, 1990, 37 ss; figs. 2,6,12.

12. Para observar la evolución de estas figuras, puede consultarse el Lexikon Iconographycum Mythologiae Classicae, sv Eros y Tempora Anni, con la bibliografía anterior.

13. La sucesión de motivos puede hacernos apuntar algunas sugerencias que, en cualquier caso, habría que comprobar; en primer lugar, la presencia de ondas o postas como banda que rodea el emblema central nos hace pensar en motivos antiguos, ya que este tipo de cenefa es propia de las primeras épocas del mosaico romano, perdiendo después importancia en favor de otros 
apuntada por la existencia entre sus cenefas de una serie de motivos de aire arcaizante, aunque dispuestos de una forma que no es exactamente antigua, y por la existencia de teselas polícromas en el emblema central, todo lo cual nos llevaría a un siglo II o comienzos del III sin ninguna posibilidad de precisar, a falta de un estudio detenido que aún no hemos podido desarrollar.

En cuanto al sectile que pavimenta una de las estancias contiguas, la aparición de un motivo similar en una colección privada de Sevilla, procedente de Itálica, nos sirve para documentar la extensión del motivo, aunque poco nos ayuda a precisar su cronología ${ }^{14}$.

\section{Conjunto 6-7-8}

De este grupo de mosaicos, el único que merece la pena destacar es el número 7, pues muestra una superficie de esvásticas enlazadas que rodean un emblema central totalmente perdido. Rasgos destacados son la forma de enlazar las esvásticas y hecho de que el motivo principal sea en blanco sobre negro, ya que lo normal en este tipo de composiciones es que el dibujo sea negro sobre blanco.

El tema de las esvásticas es extraordinariamente frecuente en todo el ámbito romano ${ }^{15}$, como derivación de un motivo muy extendido en Grecia y en buena parte de los pueblos de la antigüedad. Mosaicos con decoración de esvásticas aparecen por todo el mundo romano, aunque de formas diferentes. Lo más frecuente, a lo largo de toda su historia, son esvásticas enlazadas formando trenzas dobles o triples, simples o compuestas, como motivo decorativo de bandas que delimitan paneles o forman un motivo central. Menos frecuente es sin embargo el mismo motivo cuando decora superficies más amplias, cuadros que forman parte de un mosaico o incluso todo el campo del mosaico. Ello ocurre sobre todo en épocas antiguas dentro de la historia del arte musivario romano, a fines de la República y comienzos del Imperio, y son frecuentes en mosaicos de opus signinum ${ }^{16}$. Más adelante este motivo es sustituido por otros más o menos complejos, y las esvásticas enlazadas se hacen bastante menos frecuentes, aunque nunca llegaron a desaparecer ${ }^{17}$. Las propias esvásticas

motivos más 'modernos'. No obstante, su aparición no quiere decir que por fuerza nos encontremos ante un mosaico antiguo. Algo parecido ocurre con la abundancia de rosetas hexapétalas, aunque aparezcan fuera ya de su ubicación original y lo hagan formando parte de varias cenefas en composiciones más o menos complejas donde, no obstante, mantienen su independencia. Las postas constituyen un motivo antiguo, aunque en la Península Ibérica aparecen con profusión entre los siglos II y IV d.C.; bien es cierto que en esta época se usan sobre todo para decorar superficies más o menos amplias, y que ya con anterioridad habían servido para decorar cenefas. En cuanto a los roleos, no merece la pena intentar siquiera el elenco de sus apariciones, pues es muy frecuente en composiciones musivas y pictóricas romanas. Tan sólo cabría destacar la aparición en este mosaico en forma de cenefas, próximo al de los erotes vendimiadores que figura con el número 3 de este catálogo.

14. Mosaico de la Era del Convento, A. García y Bellido, Colonia Aelia Augusta Italica, Madrid, 1960, págs. 134-135, fig. 53, de fecha indeterminada, quizás fines del II o comienzos del III.

15. Cf. nota 3 .

16. En zonas próximas a las de nuestro estudio, tenemos mosaicos de este tipo en Cartagena, calle del Duque número 2 y en la villa del Rihuete de Mazarrón. En el primer caso es un panel de esvásticas enlazadas que dejan entre sí cuadrados, y en el segundo un grupo de tres mosaicos de esvásticas enlazadas que cubren toda la superficie; cf. S. Ramallo, Mosaicos romanos de Carthago Nova (Hispania Citerior), Murcia, 1985, núm. 3-primeros años del siglo I dC-y 69-últimos años del siglo I a.C. ocomienzos del I d.C.). Ejemplos próximos son también los de los mosaicos de opus signinum de Velilla de Ebro y de Castejón, datados por sus excavadores en 10-54 d.C.; cf. D. Fernández Galiano, Mosaicos romanos del Convento Cesaraugustano, Zaragoza, 1987, núm. 67.

17. No obstante, siguen apareciendo. Así, por ejemplo, en las Salles de Passage III y IV de Thuburbo Maius, pero ya en la forma característica de esvásticas enlazadas que dejan entre sí espacios para pequeños cuadrados; cf. A. Alexander y M. Ennaifer, Corpus de Mosaïques de Tunisie, Les mosaiques de la region du forum, Túnez, 1980, pp. 7-8, datados en la segunda mitad del siglo II d.C. También en Saint Romain en Gal, asimismo con cuadritos entre las esvásticas, fechados de forma aproximada en el siglo II; cf. J. Lancha, Recueil Général des mosaïques de la Gaule, III, Narbonnaise, 2, París, 1981, num. 408. 
dejan de ser las simples líneas de sus primeros momentos y se convierten en bandas rellenas por cables de diversos tipos.

En este sentido, el mosaico número 9 de los Baños de la Reina de Calpe parece relacionarse con los grupos más antiguos de mosaicos de esvásticas. Y el hecho -único en Calpe- de que el dibujo sea blanco sobre negro podríamos considerarlo o bien como un testimonio de una época algo más avanzada, en el momento en que se pone de moda este tipo de decoración, o bien como un elemento que apunta hacia una cronología más antigua, motivado por el hecho de que en los mosaicos de opus signinum, en los que resultan tan frecuentes decoraciones de este tipo, el color blanco de las teselas -sean tales o sean simples guijarros- destaca casi siempre sobre el fondo rojizo propio del mortero.

\section{CONCLUSIONES}

Resulta muy difícil, por todo lo apuntado anteriormente, obtener conclusiones acerca de la cronología y destino de los mosaicos. Parece, de todas formas, que estos conjuntos de mosaicos mantienen una cierta relación entre sí, propiciada por algunos de los motivos decorativos, que se repiten con más o menos exactitud en varios de los grupos. Ello puede deberse o bien a una contemporaneidad de todos los conjuntos o bien -lo que creemos más probable- al conocimiento visual de uno de ellos a la hora de realizar el siguiente; y también, posiblemente, a la existencia de un repertorio limitado de motivos decorativos y ornamentales por parte de los artesanos autores de las diferentes piezas.

Si nos viéramos obligados no obstante a realizar una seriación cronológica, propondríamos, con toda clase de reservas, una mayor antiguiedad para los mosaicos de los conjuntos 1-2-3-4 y 6-7-8 sobre los del 5-9, dentro de un ámbito cronológico de los siglos I-II d.C. Mayores precisiones podrían establecerse a partir del motivo decorativo del pavimento número 7 y de su estrecha relación compositiva con los mosaicos de opus signinum, que primaría sobre el estilo blanco sobre negro, en la forma apuntada más arriba. De ser cierta esta apreciación, el mosaico podría corresponder a un momento de coexistencia con los opera signina, y datarse por tanto hacia el cambio de Era o en las décadas inmediatamente posteriores.

El segundo conjunto, mosaicos 1-2-3-4 correspondería, a causa de la decoración de casetones separados por cenefas que parecen más antiguas, y de la escena de vendimia de otra de las habitaciones, a las primeras décadas del siglo II d.C. La semejanza de algunos de los motivos -roleos, peltas-y el aire 'antiguo' que desprenden otros -postas, rosetas de seis puntas-, junto con el carácter polícromo de su emblema central, nos hacen proponer para el conjunto 5-9 una cronología algo posterior, tal vez momentos avanzados del siglo II d.C. o más bien comienzos del III ${ }^{18}$. Todo ello, como es lógico, a reservas de lo que el más detenido estudio de los propios mosaicos y de su contexto arqueológico que actualmente se encuentra en curso pueda deparar.

18. Estas cronologías vienen a coincidir, grosso modo, con las propuestas en el estudio arqueológico, aunque se ha llegado a ello por caminos distintos; cf. Abascal, Sala y Cebrián citado en nota 1. 

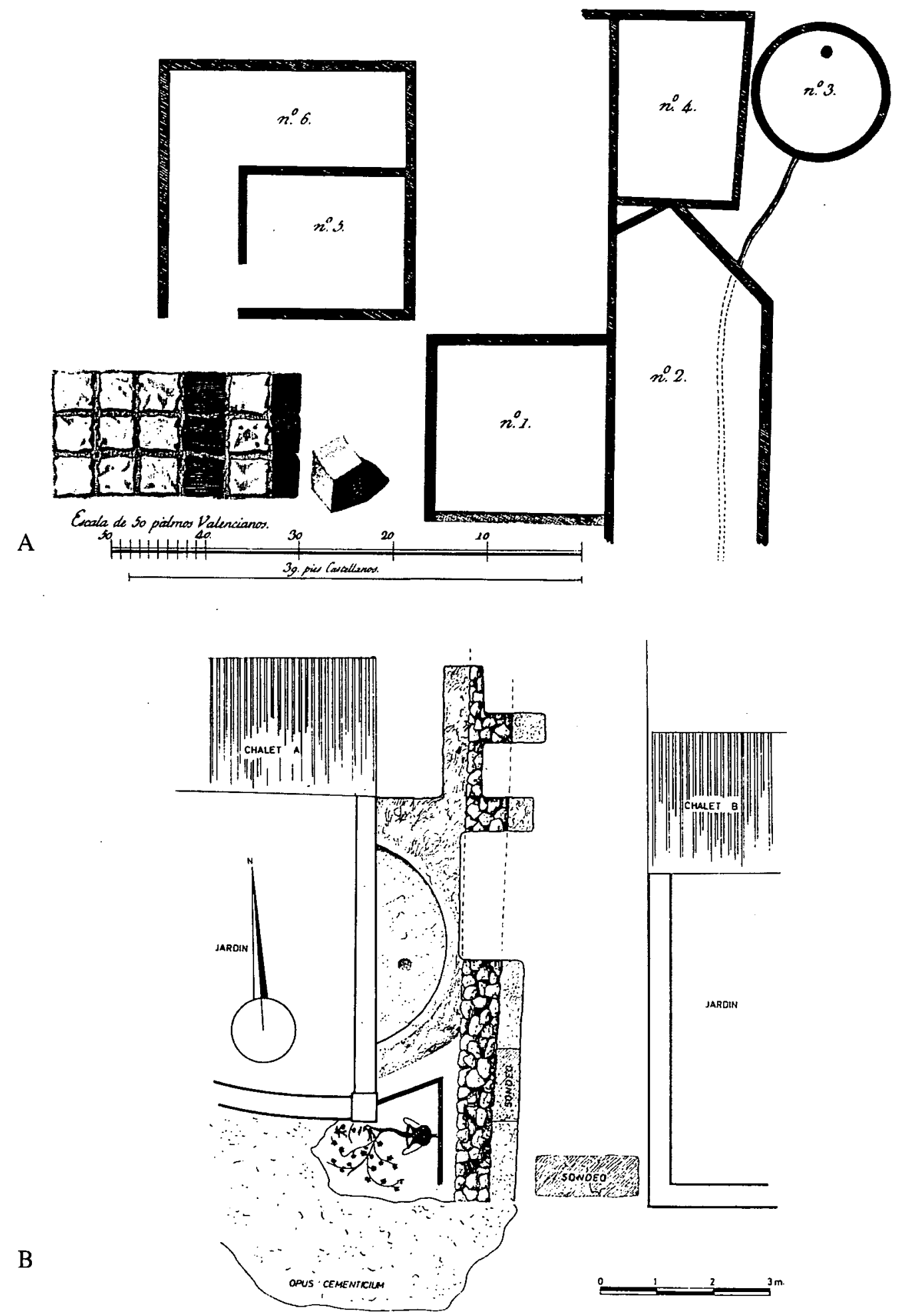

Fig. 1. Áreas excavadas por Cavanilles (A) y Pellicer (B). 


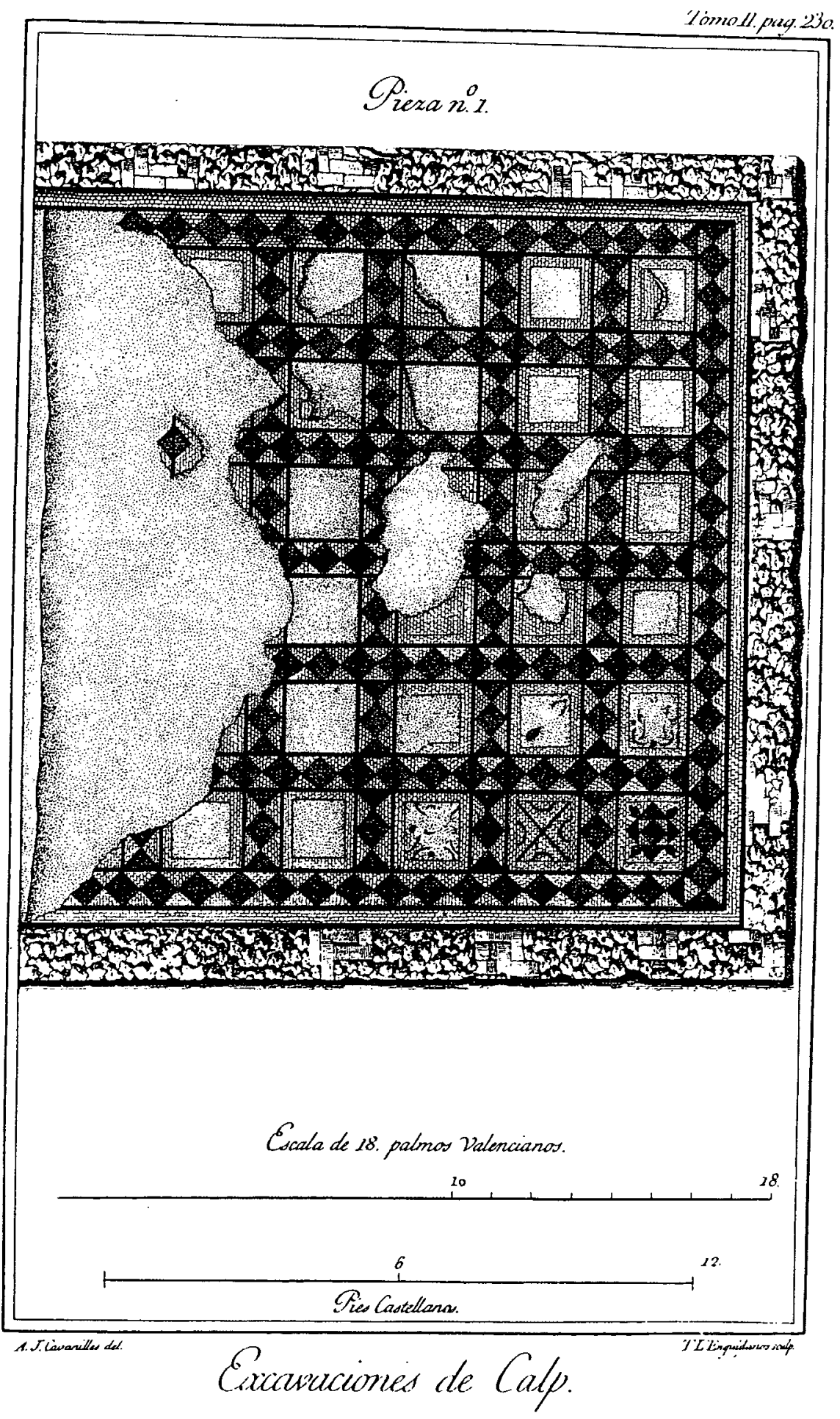

Fig. 2. Mosaico número 1 según dibujo de Cavanilles. 


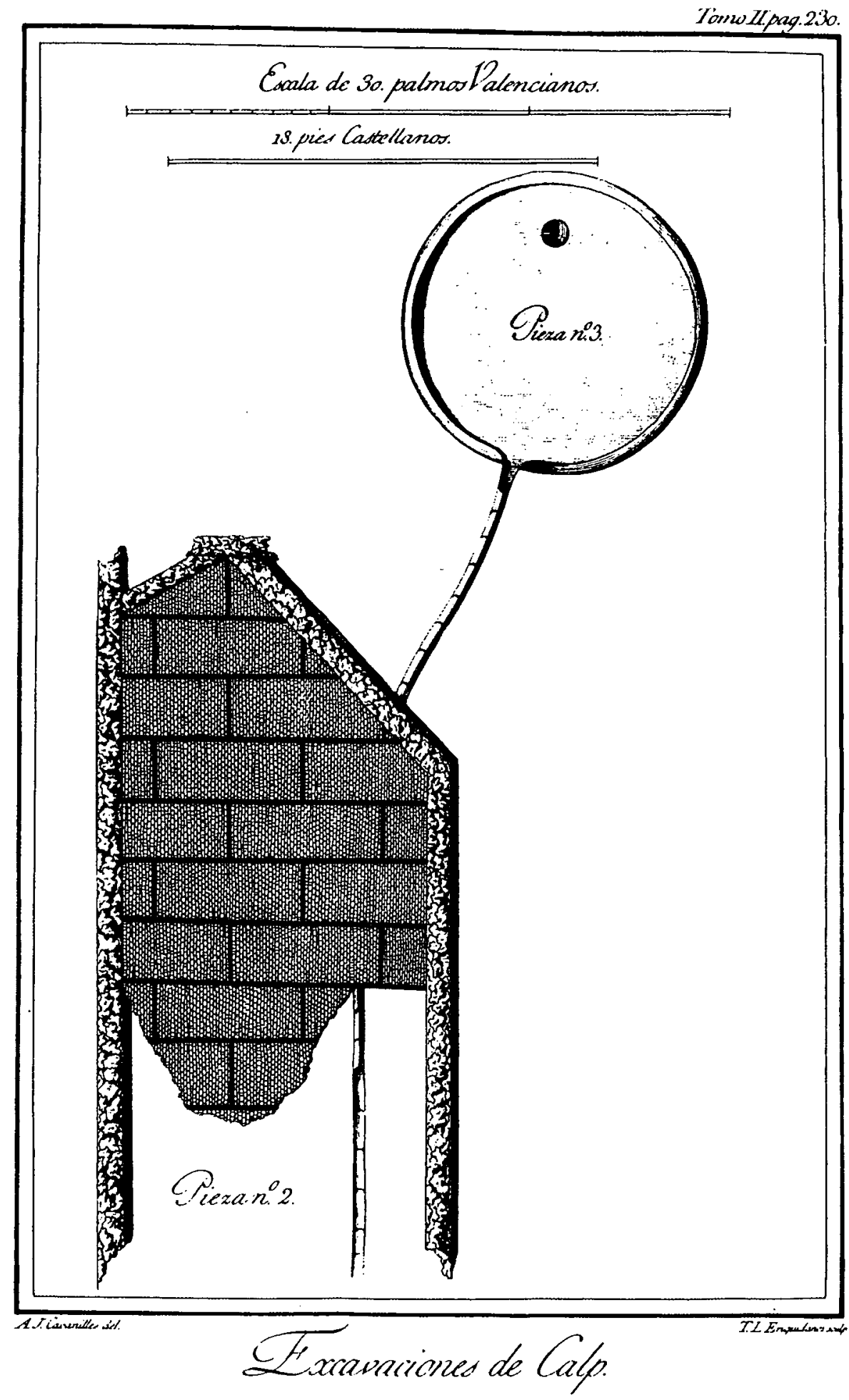

Fig.3. Mosaico número 2 según dibujo de Cavanilles. 


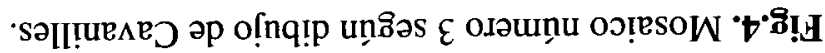

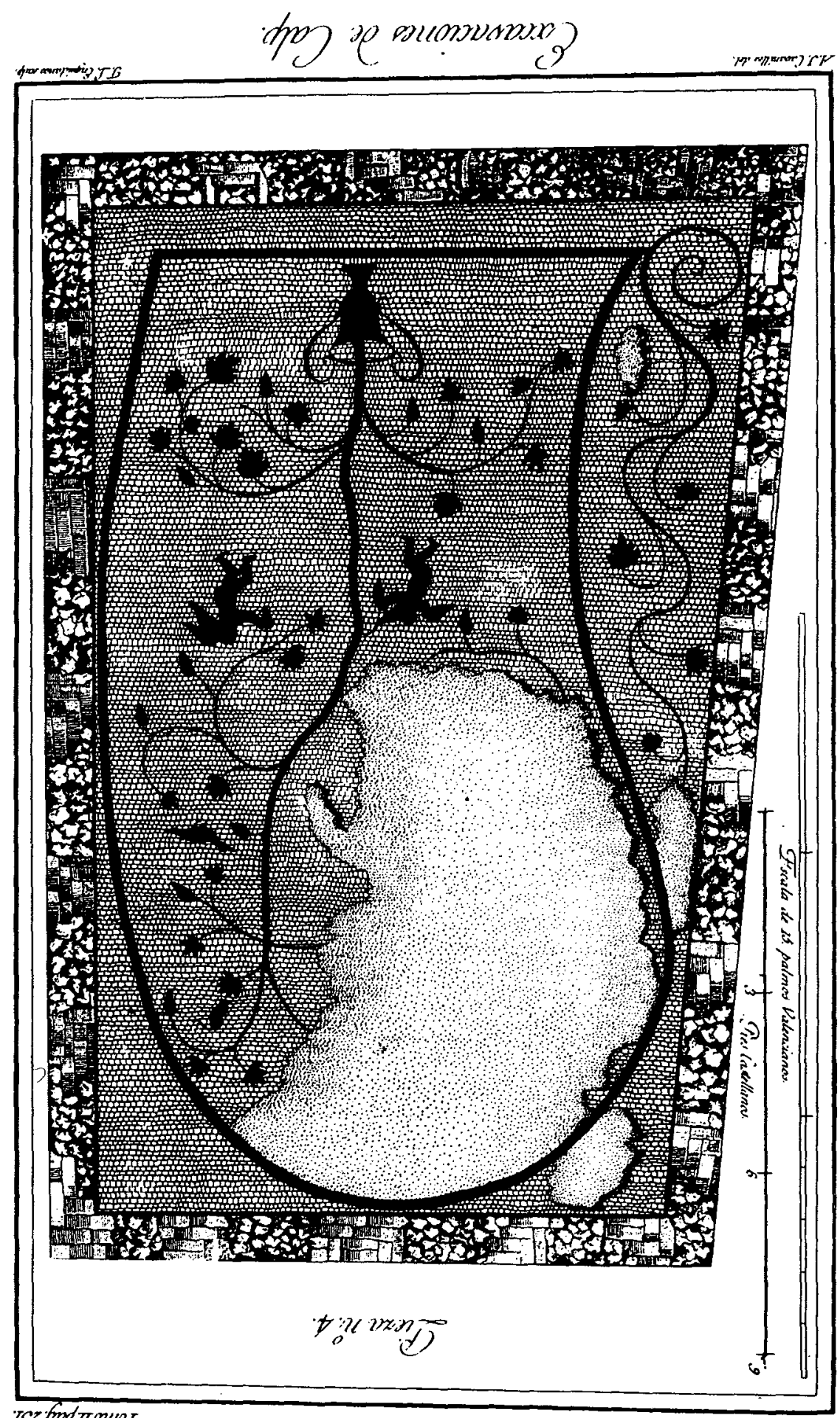

TE. bod Troue 


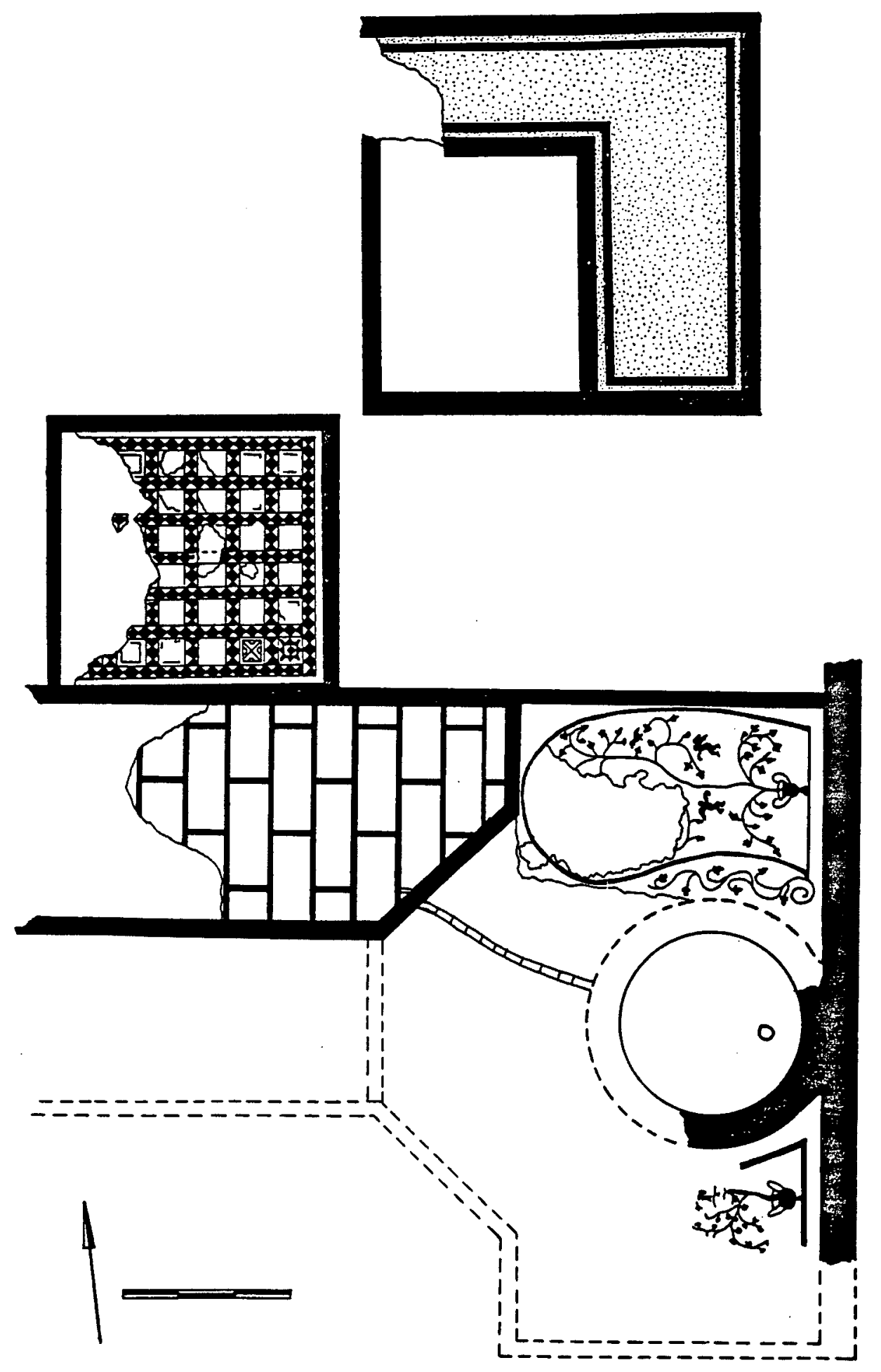

Fig. 5. Composición de los mosaicos dibujados por Cavanilles y del excavado por Pellicer según J.M. Abascal. 


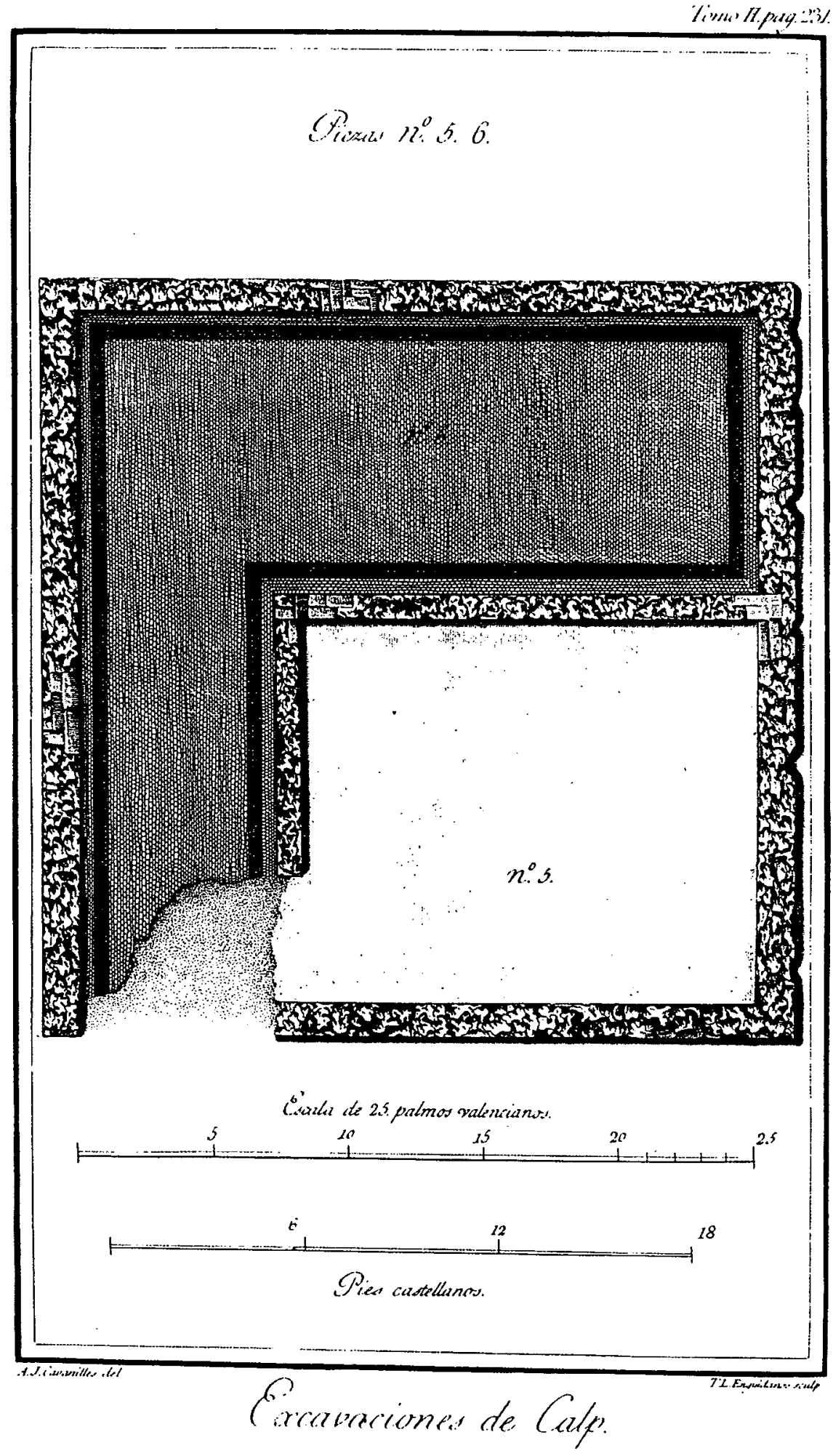

Fig. 6. Mosaico número 4 de Cavanilles. 


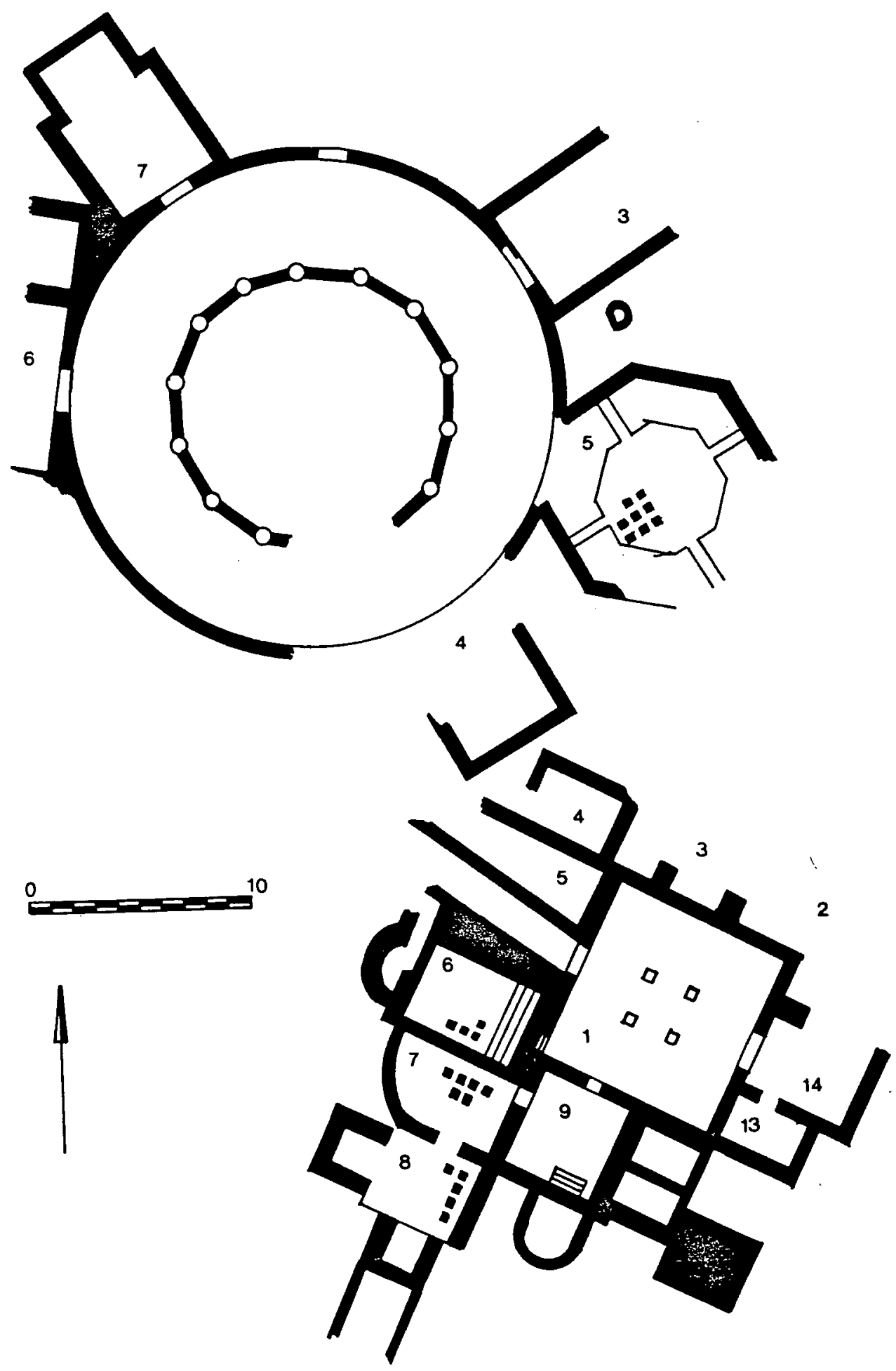

Fig. 7. Áreas excavadas en los años 80-90; patio poligonal (arriba) y zona termal (abajo) según J.M. Abascal. 


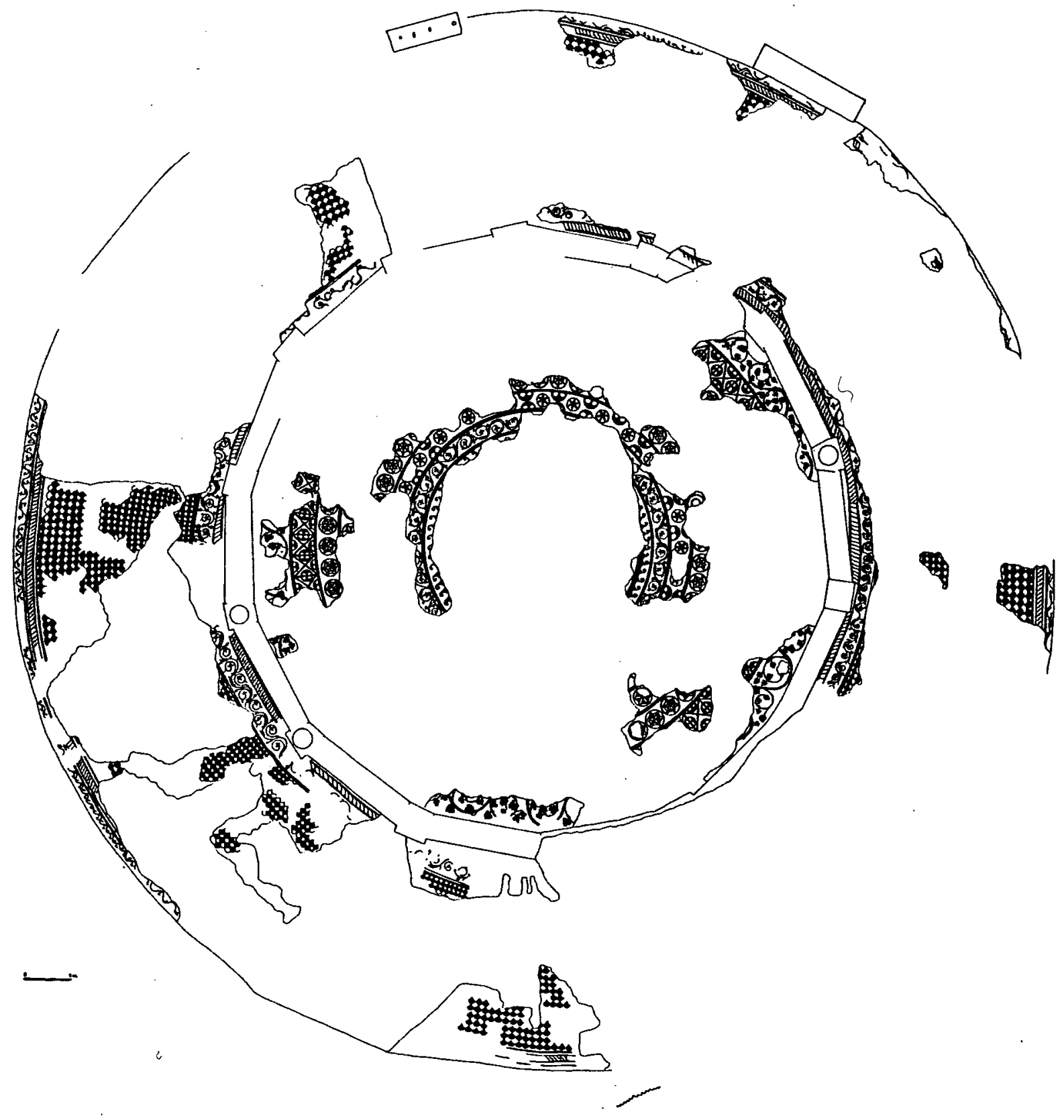

Fig. 8. Dibujo de las zonas conservadas del mosaico del patio (número 5) según J.M. Abascal. 


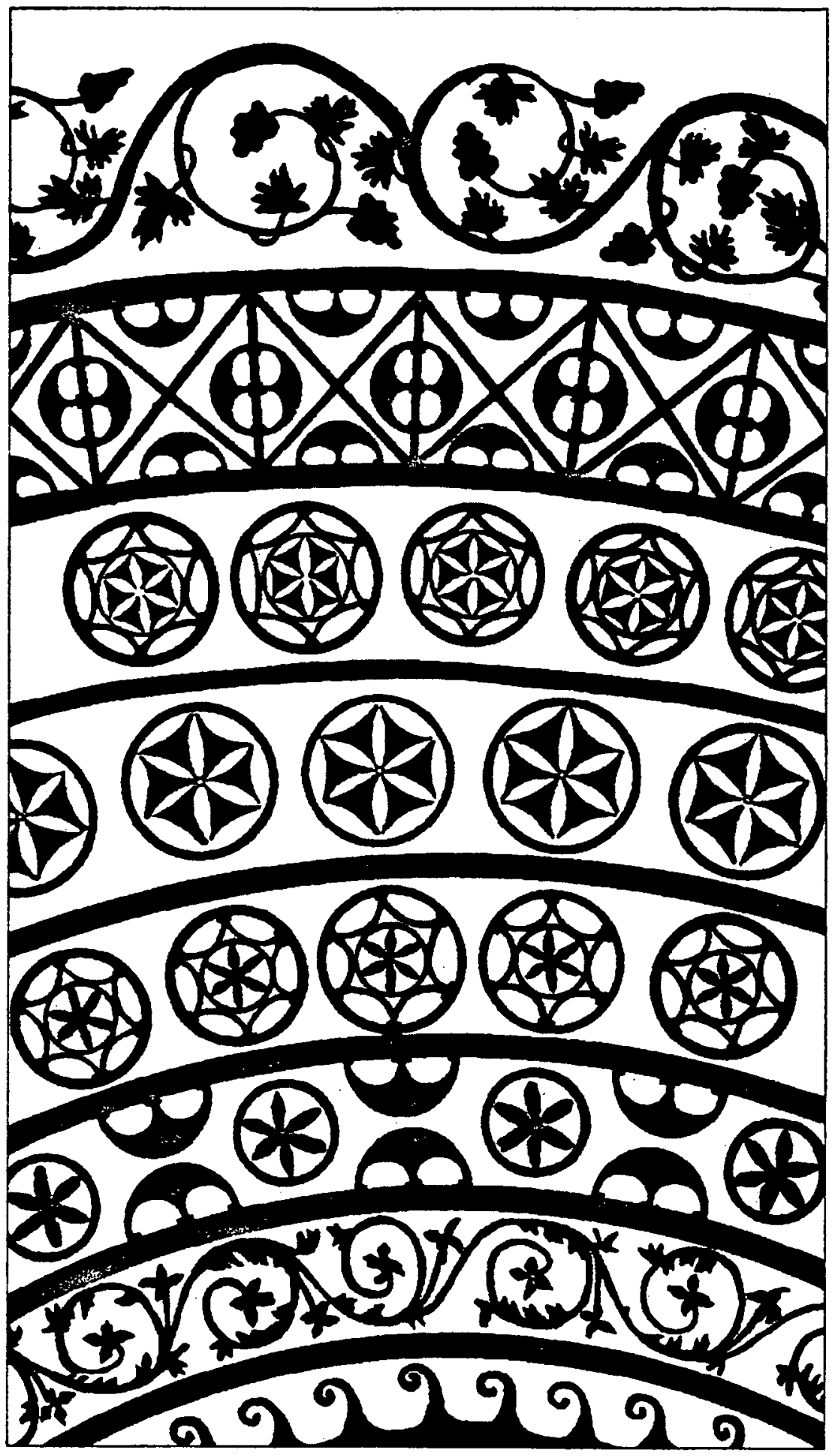

Fig. 9. Sucesión ideal de las cenefas decorativas del segundo cuerpo del mosaico número 5 según J.M. Abascal. 


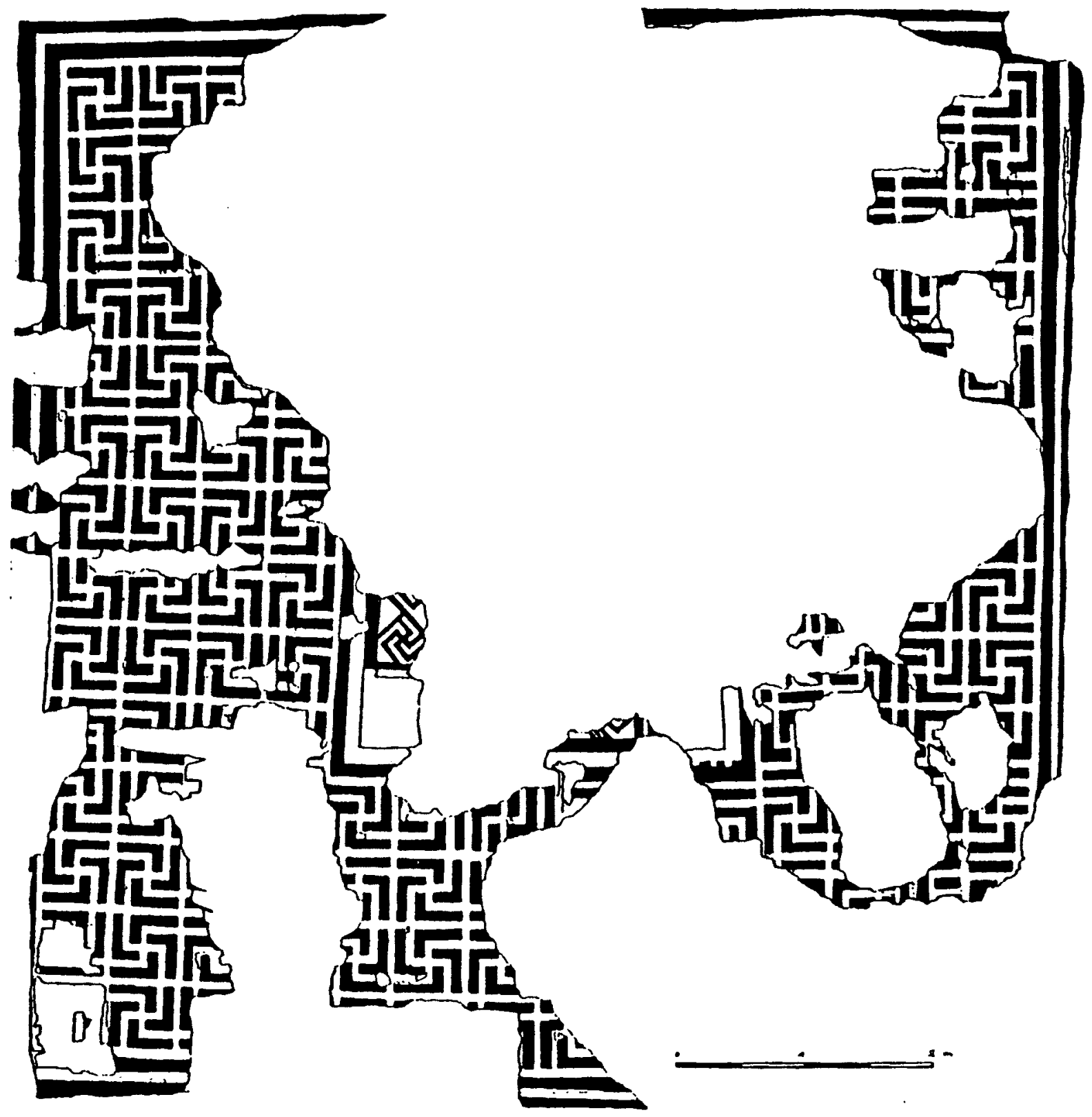

Fig. 10. Mosaico de una estancia de las termas según J.M. Abascal. 


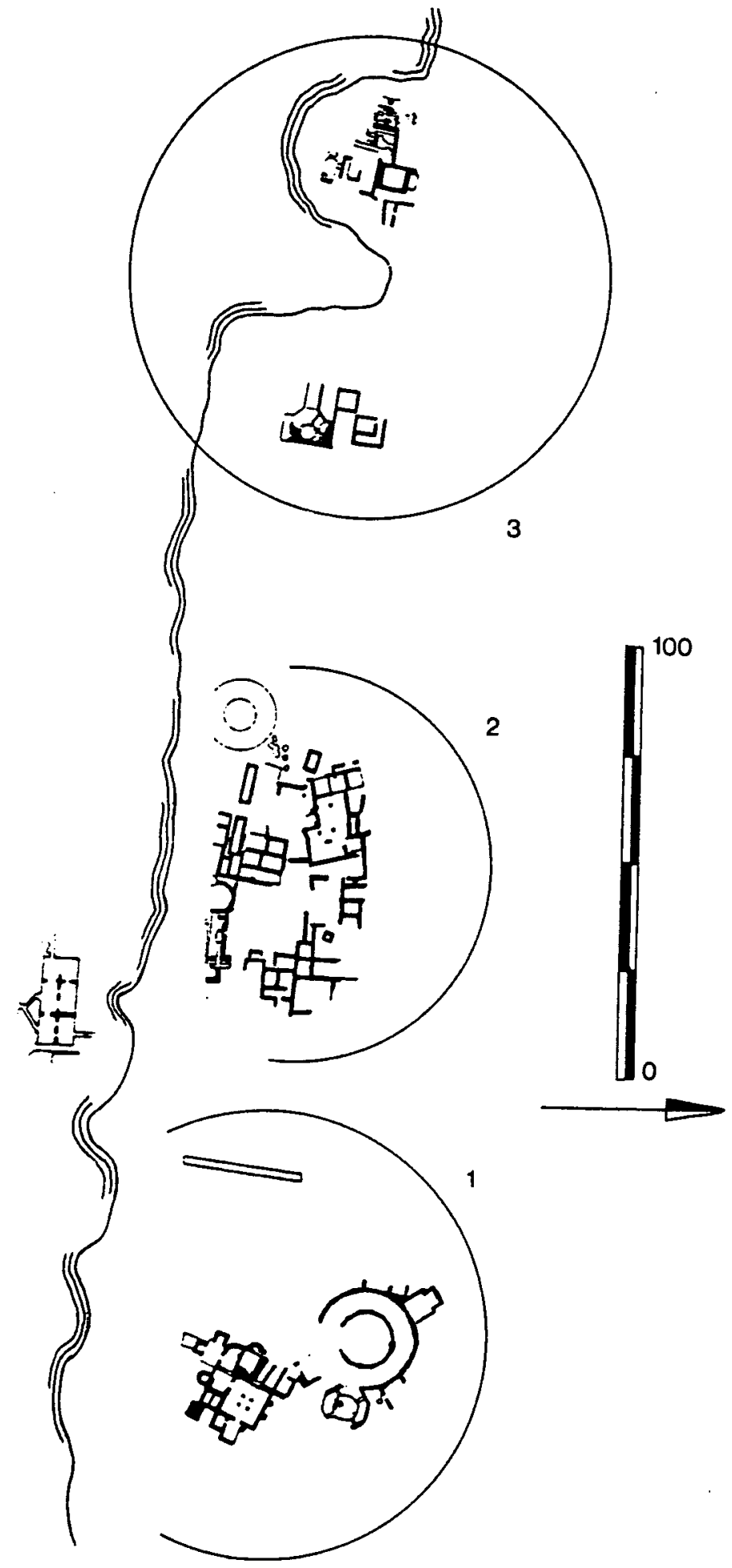

Fig. 11. Áreas excavadas. Los mosaicos se concentran al sur de la zona 3 y en la zona 1 según J.M. Abascal. 


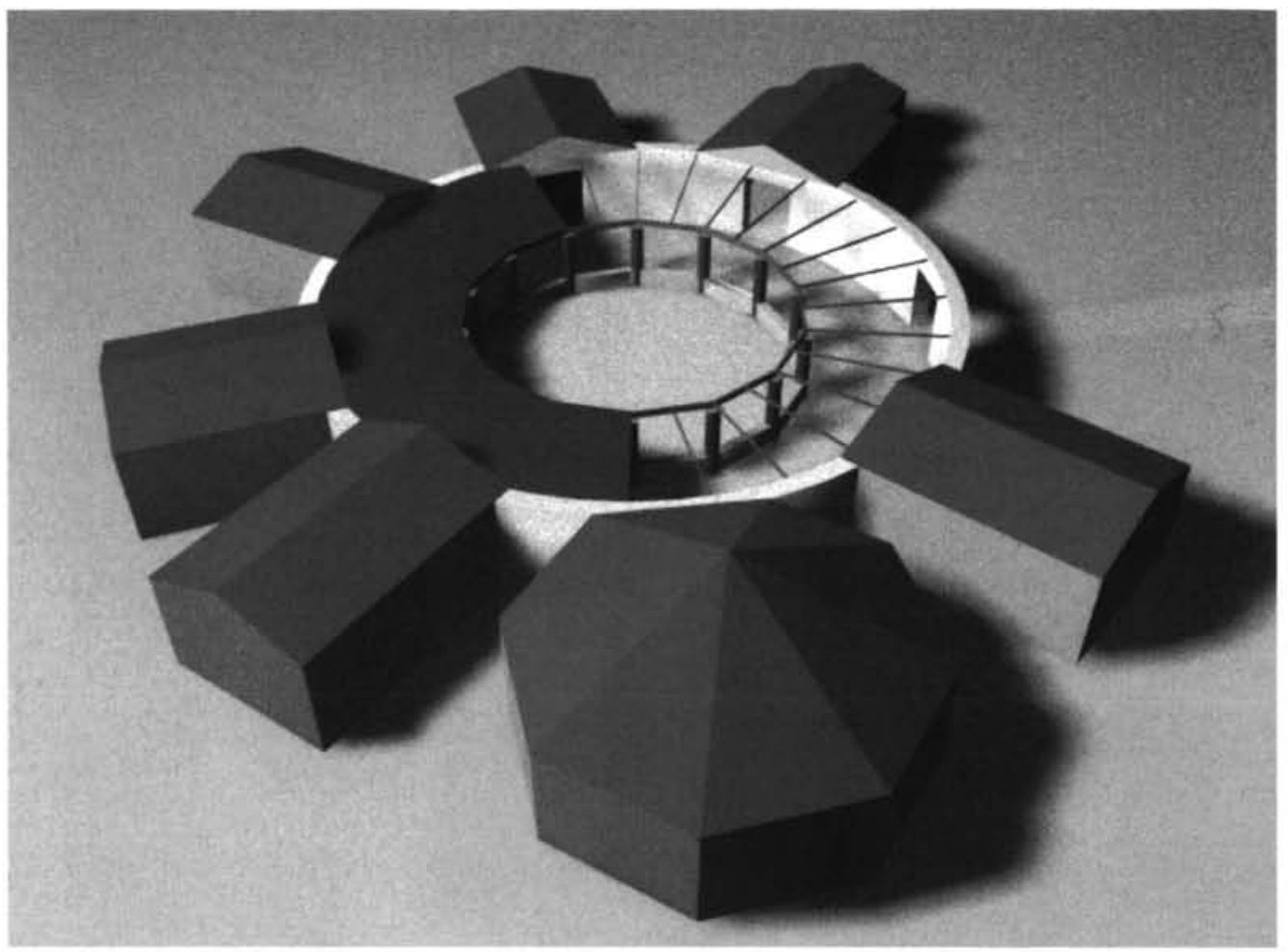

Lám. 1. Propuesta de restitución del patio poligonal y estructuras anejas según D. Valls.

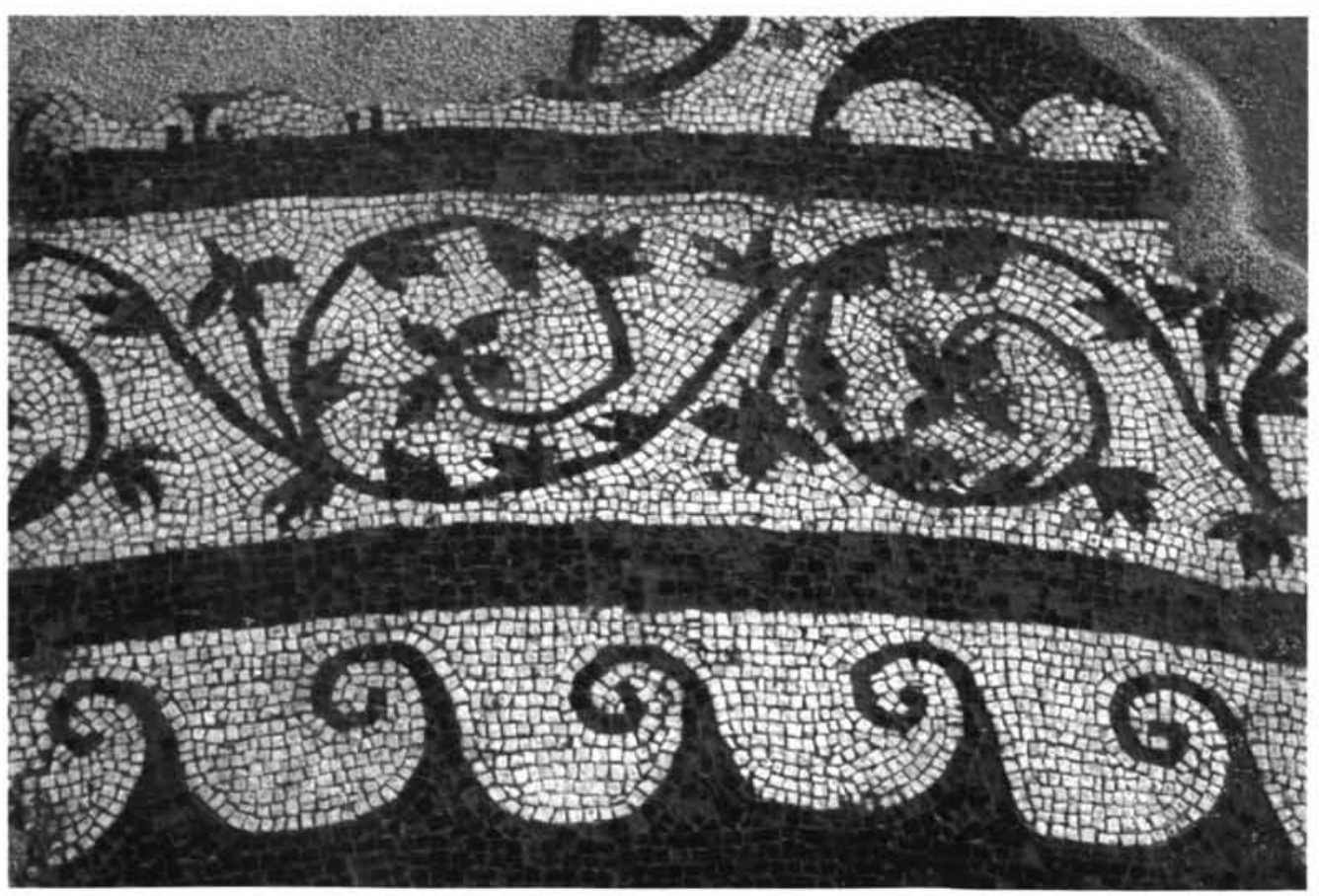

Lám. 2. Cenefas que rodean el emblema en el mosaico número 5. Foto J.M. Abascal. 


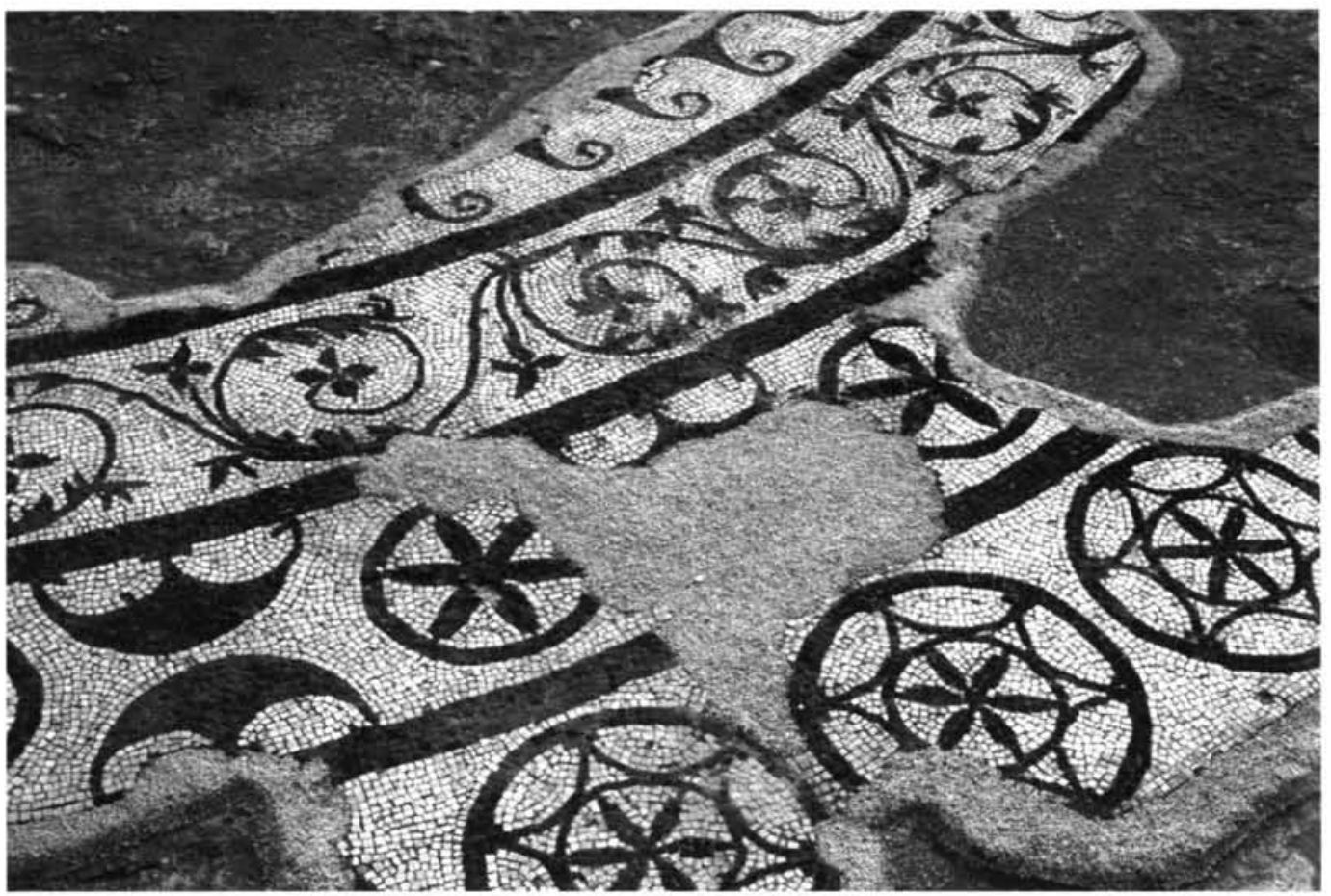

Lám. 3. Cenefas que rodean el emblema en el mosaico número 5. Foto J.M. Abascal.

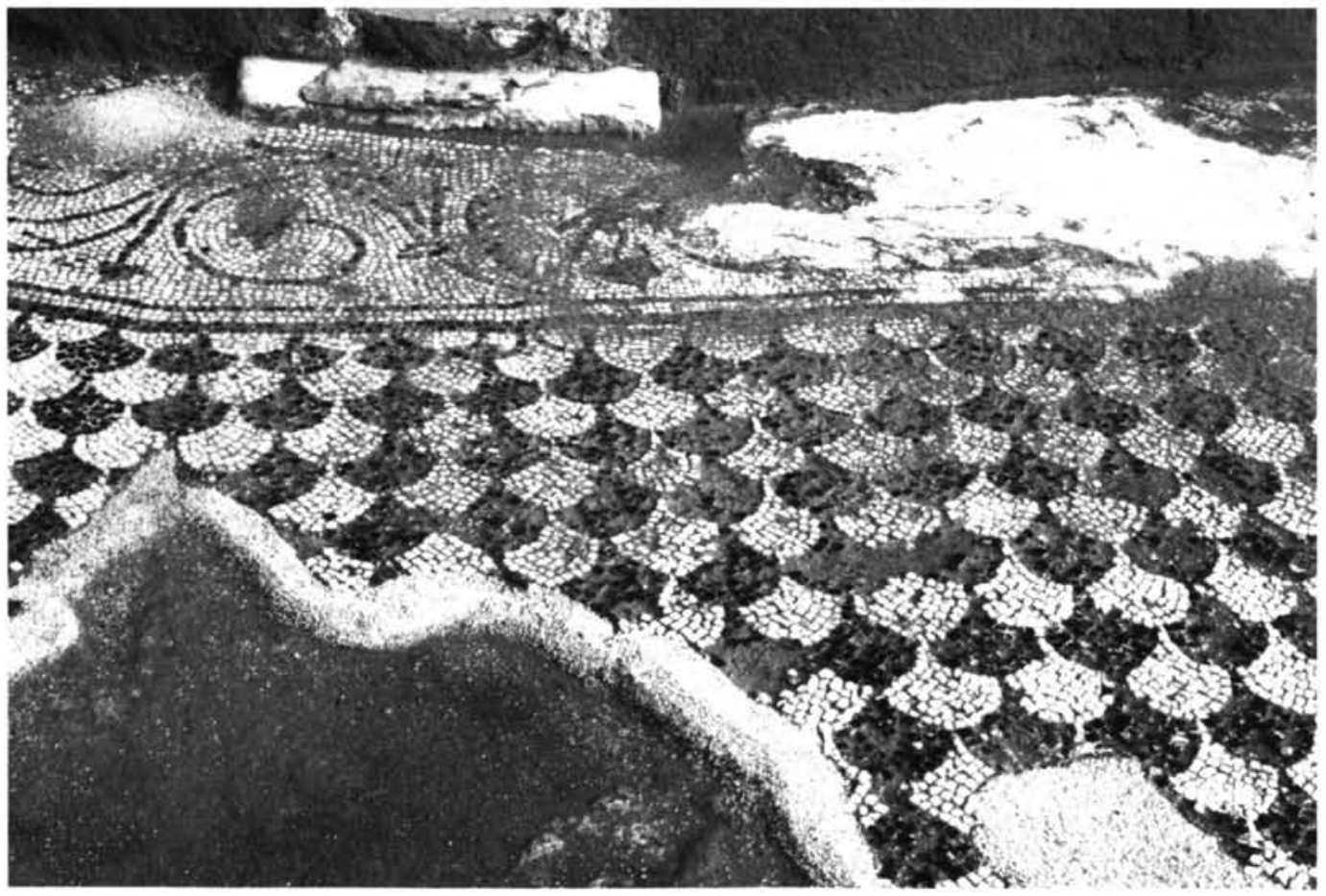

Lám. 4. Campo de escamas imbricadas del mosaico número 5. Foto J.M. Abascal. 


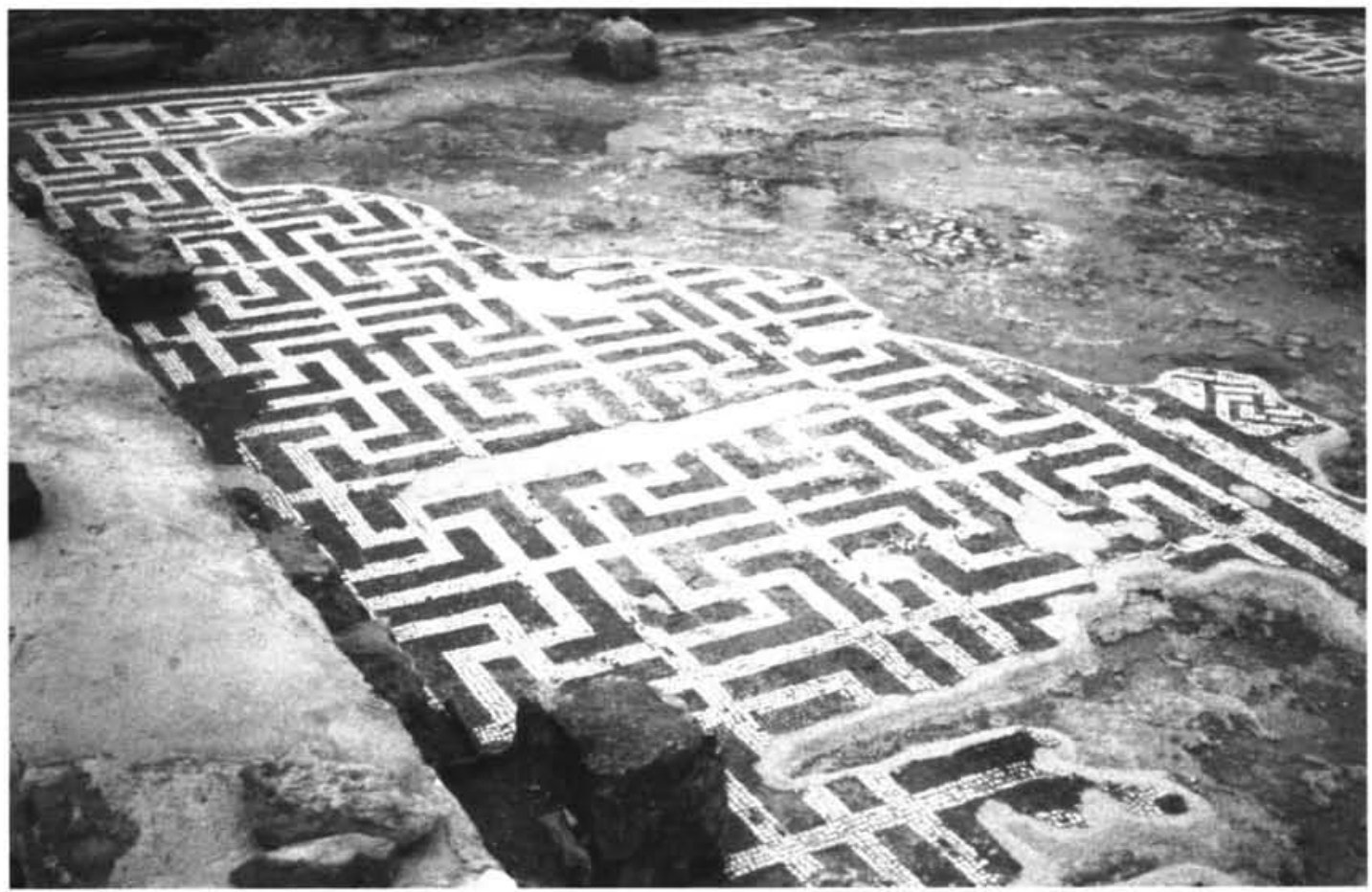

Lám. 5. Mosaico número 6. Foto J.M. Abascal.

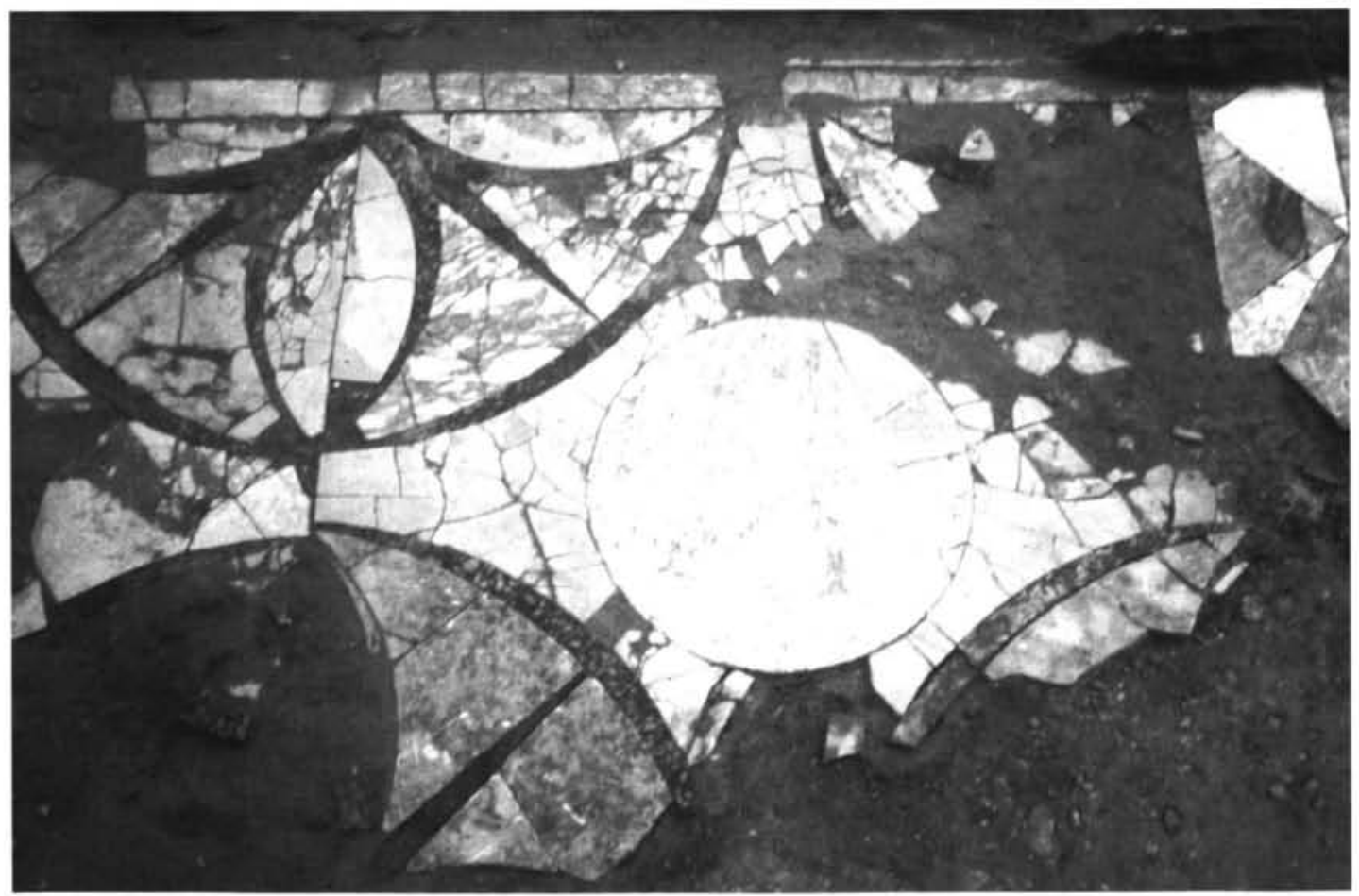

Lám. 6. Mosaico de opus sectile. Foto J.M. Abascal. 


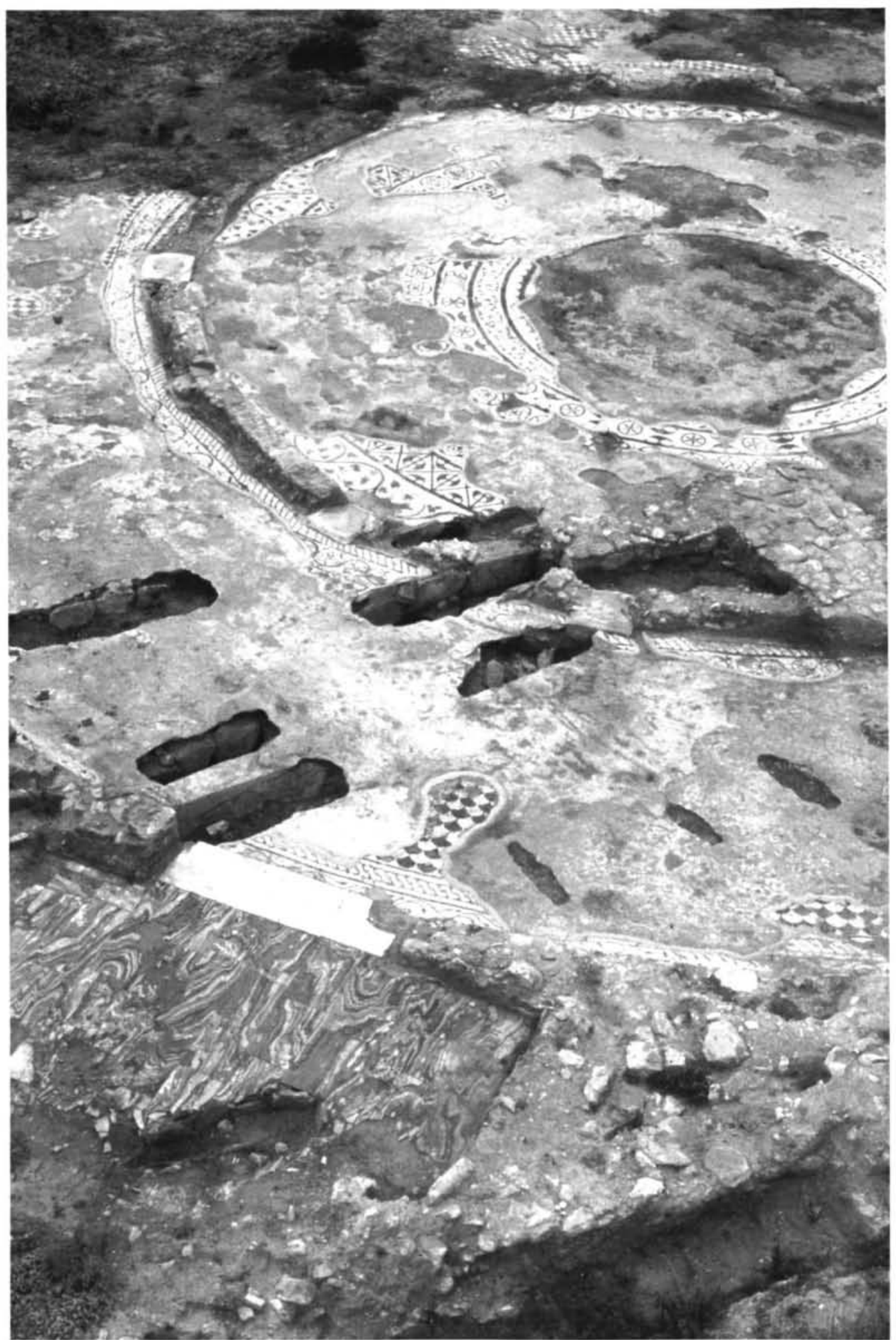

Lám. 7. Vista general del patio poligonal. Foto J.M. Abascal. 